\title{
Uptake and Excretion of Cobalt by Sea Cucumber Stichopus japonicus and Prawn Penaeus japonicus
}

\author{
Yuzuru Suzuki*, Motokazu NAKahara*, Ryoichi NaKamura* \\ and Taishi UeDA*
}

(Received March 23, 1982)

\begin{abstract}
Radiocobalt tracer experiments were carried out to obtain further information on the biochemical behavior of this nuclide in sea cucumber and prawn. The biological half lives of ${ }^{60} \mathrm{Co}$ (inorganic cobalt in sea water) were calculated at 73 days for sea cucumber and 24 days for prawn. The ${ }^{80} \mathrm{Co}$-binding constituents in the organs and tissues of these organisms were extracted with a Tris-acetate buffer solution and separated using gel filtration on Sephadex G-75. Although most radioactivity $(86 \%)$ in the crude extraction of sea cucumber (without intestine) was found in a relatively high molecular weight fraction (more than 8000 ), that in prawn liver was observed in a low molecular weight fraction (less than 5000). From analysis for carbohydrates, a large portion of carbohydrates in the prawn liver was found in the high molecular fraction, however, the presence was observed in the low molecular weight fraction, too. Further characterization by electrophoresis showed that this fraction contained at least four ${ }^{60} \mathrm{Co}$-binding proteins or peptides and significant quantities of ${ }^{\circ 0} \mathrm{Co}$-binding carbohydrates.
\end{abstract}

The biological role and detailed chemical nature of the components await further study.

It is important to gain more information on the biochemical behavior of radionuclides for elucidation of the mechanism of radioactive contamination of marine organisms. And this is also necessary for accurate estimation of the internal radiation doses to man by the intake of radioactive marine foods. As a part of studies on the metabolism of radionuclides in marine organisms, we have reported on the uptake-excretion pattern of radionuclides through environmental water, ${ }^{1-4)}$ food $^{3,0)}$ and sediment ${ }^{3-11}$ and the binding of radionuclides to the constituent materials in fish, ${ }^{12)}$ mollusca ${ }^{13)}$ and algae. ${ }^{14)}$

In the present study, radioisotope tracer experiments were carried out using sea cucumber (as a coelenterata) and prawn (as a crustacea) because of few information available on the contamination of these organisms by radioactive cobalt. Furthermore, sea cucumber as well as prawn is often eaten in Japan, and also prawn plays an important role as a food organism on food chain in coastal marine ecosystem.

The experiments reported here were designed to examine the uptake and excretion of radioactive cobalt through sea water by these marine organisms and the binding of this radionuclide to the consti- tuent materials in them.

\section{Materials and Methods}

\section{Uptake and Excretion of ${ }^{\circ 0} \mathrm{Co}$ by Sea Cucumber}

Two hundred $\mu \mathrm{Ci}$ of ${ }^{80} \mathrm{Co}\left({ }^{\circ} \mathrm{CoCl}_{2}\right.$ from the Radiochemical Centre of U. K.) were added into an acrylic tank containing 100 liters of sea water with sufficient aeration. The temperature of the rearing sea water was maintained at $20 \pm 2{ }^{\circ} \mathrm{C}$ during the experiments. Ten individuals of sea cucumber Stichopus japonicus (average body weight; $200 \mathrm{~g}$ ) were placed in the tank. After exposure for a week, these organisms were transferred to an acrylic tank containing 100 liters of nonradioactive sea water and fed for six weeks after the commencement of the excretion experiment. The rearing sea water was frequently replaced with fresh sea water so as to remove the radioactive substances excreted from the sea cucumbers. In the uptake and excretion experiments, the ten individuals of sea cucumber were taken out of the tank and each organism was weighed and wrapped with a polyethylene bag. And then the whole body radioactivity of each sea cucumber was measured with a "Armac" $4 \pi$-scintillation counter

* Division of Marine Radioecology, National Institute of Radiological Sciences, Isozaki, Nakaminato,

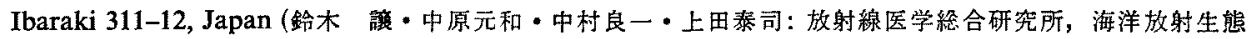
学研究部). 
(Packard Co. Model 446). They were replaced into the tank immediately after the measurement. This procedure was repeated 11 times throughout the uptake and excretion experiments. The value obtained at every measurement was standardized in $\mathrm{cpm} / \mathrm{g}$ of organism as a mean of ten samples.

Uptake and Excretion of Inorganic Cobalt-60 and Organic Cobalt-57 by Prawn

Four hundred $\mu \mathrm{Ci}$ of ${ }^{\circ 0} \mathrm{Co}\left({ }^{\circ} \mathrm{CoCl}_{2}\right)$ as an inorganic cobalt in the medium were added into an acrylic tank containing 100 liters of sea water, and then 30 individuals of prawn Penaeus japonicus (average body weight, $7.6 \mathrm{~g}$ ) were placed in the tank. While, $20 \mu \mathrm{Ci}$ of ${ }^{87} \mathrm{Co}\left({ }^{87} \mathrm{Co}\right.$-cyanocobalamin from the Radiochemical Centre of U.K.) as an organic cobalt in the medium were added into a glass beaker containing 4 liters of sea water and 10 individuals of prawn were fed. The ${ }^{57} \mathrm{Co}$ was added once a day so that the radioactivity level in the sea water was kept constant. After exposure for a week, the prawns marked by ${ }^{80} \mathrm{Co}$ or ${ }^{67} \mathrm{Co}$ were transferred to the excretion experiment. The radioactivity in the whole body of prawn was measured in the similar manner as above. At the 7 th day of the uptake experiment, 5 individuals of prawn were taken out of each aquarium, and dissected into 9 parts such as shell, muscle, liver, gill, eyes, legs, intestine, stomach and the others (blood, body fluid etc.) so as to determine different distribution pattern between ${ }^{87} \mathrm{Co}$ and ${ }^{80} \mathrm{Co}$ in the prawns. And then the radioactivity in each organ and tissue was measured with a well type gamma ray counter with an automatic sample changer (Aloka Auto well gamma system, JDC-752).

\section{Binding of Radioactive Cobalt to the Constituents in the Samples}

The muscle and the intestine of sea cucumber and the liver of prawn were separately homogenized with about $7 \mathrm{~m} l$ of $0.025 \mathrm{M}$ Tris-acetate buffer solution ( $\mathrm{pH}, 8.4)$ by a high speed homogenizer $(20000$ $\mathrm{rpm}$ ) and centrifuged at $10000 \mathrm{rpm}$ for $40 \mathrm{~min}$. This procedure was repeated twice, and a large portion of crude extract obtained $(10 \mathrm{ml})$ was applied to a Sephadex G-75 gel column ( $20 \mathrm{~mm} \phi \times$ $70 \mathrm{~cm}$ ) equilibrated with the same buffer solution. The gel filtration was operated at a flow rate of $40 \mathrm{~m} l / \mathrm{h}$ using the same buffer solution. The 50 fractions of $5 \mathrm{~m} l$ each were taken in a fraction collector and the radioactivity in them was measured with a well type gamma ray counter mentioned above. The extraction percent of radioactivity in this procedure was approximately $85 \%$ for the muscle, $83 \%$ for the intestine of sea cucumber and $87 \%$ for the liver of prawn, respectively. After the radioactivity in each fraction was measured, the soluble protein content in them was determined by measurement of absorbancy at $280 \mathrm{~nm}$ with a spectrophotometer (Hitachi 124 DB). The molecular weight of protein was estimated on the basis of a calibration curve that was obtained using molecular weight markers such as catalase $(\mathbf{M}=$ 230000), ribonuclease $A(M=13700)$, cytochrome $C(M=12400)$, insulin $(M=6000)$ and cyanocobalamin $(M=1360)$. Furthermore, the carbohydrate present in the liver of prawn contaminated by ${ }^{\circ 0} \mathrm{Co}$ and the column fractions was determined using the phenol/sulfuric acid procedure ${ }^{15)}$ and the resultant absorption maximum at 480 to $490 \mathrm{~nm}$. Electrophoresis of the peak fractions from the $\mathbf{G}$ 75 chromatography that had been concentrated by freeze-drying was performed in board polyacrylamide gels $(6.5 \%$ at $\mathrm{pH} 8.9,130 \mathrm{~V} 95 \mathrm{~mA}$, for 4.5 hours. ${ }^{10)}$

\section{Results and Discussion}

\section{Uptake and Excretion of ${ }^{\circ} \mathrm{Co}$ by Sea Cucumber}

Fig. 1 shows an uptake-excretion curve of ${ }^{80} \mathrm{Co}$

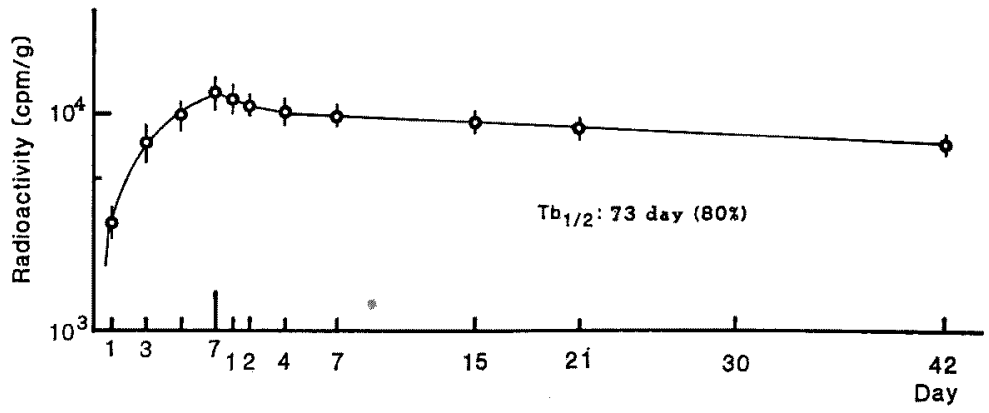

Fig. 1. Uptake-excretion of ${ }^{80} \mathrm{Co}$ through sea water by sea cucumber Stichopus japonicus. 
in the whole body of sea cucumber through environmental sea water. The radioactivity ratios (AR: concentration of radiocobalt in organism/concentration of radiocobalt in sea water) in 7 days after exposure were calculated as 8 for the whole body and 20 for the intestine. The ${ }^{80} \mathrm{Co}$ distribution $(\%)$ in the sea cucumber was $75 \%$ for the muscle, $18 \%$ for the intestine and $7 \%$ for the body fluid, and it little varied throughout the period of this experiment. The ${ }^{\circ 0} \mathrm{Co}$ excretion rate was relatively slow, and approximately $60 \%$ of the initial radioactivity was retained even after 6 weeks. The ${ }^{80} \mathrm{Co}$ turnover rate $\left(\mathrm{day}^{-1}\right)$ corresponding to $80 \%$ of retention radioactivity was 0.0095 in long component, and the biological half life was calculated at 73 days. These values indicate that a sea cucumber does not easily excrete organically bound cobalt.

\section{Uptake and Excretion of ${ }^{60} \mathrm{Co}$ and ${ }^{57} \mathrm{Co}$ by Prawn}

The chemical form of the element in the environment is an important feature in the ability of the organism to retain it in the body tissues. Fig. 2 shows uptake-excretion curves of ${ }^{57} \mathrm{Co}$ and ${ }^{80} \mathrm{Co}$ in the whole body of prawn through environmental sea water containing an organic or an inorganic radiocobalt. In this Figure, it is impractical to compare quantitatively ${ }^{57} \mathrm{Co}$ radioactivity with ${ }^{80} \mathrm{Co}$ radioactivity because of different experimental condition, however it is possible to observe the uptake-excretion tendency. The shape of these

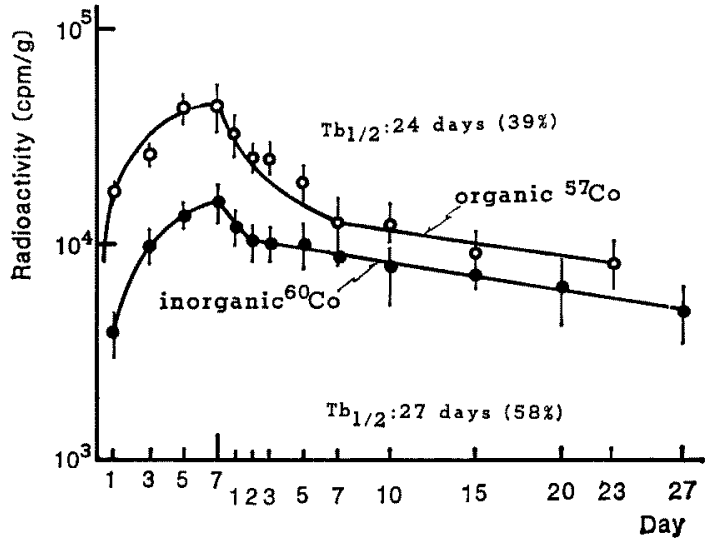

Fig. 2. Uptake-excretion of organic or inorganic cobalt through sea water by prawn Penaeus japonicus.

curves was almost the same as those already reported. ${ }^{1,3,12)}$ An approximately exponential relationship exists with the slope, turnover rate $\left(\mathrm{day}^{-1}\right.$ ) of 0.0284 for ${ }^{87} \mathrm{Co}$ and 0.0257 for ${ }^{80} \mathrm{Co}$ in the long components, after a rapid decrease during the first several days. The biological half lives of ${ }^{87} \mathrm{Co}$ and ${ }^{80} \mathrm{Co}$ were calculated at 24 days and 27 days, respectively. Cobalt is associated with the organism as constituents reactive biological molecules, but not firmly incorporated into tissues, and forming complexes in the biological surfaces. ${ }^{17}$ )

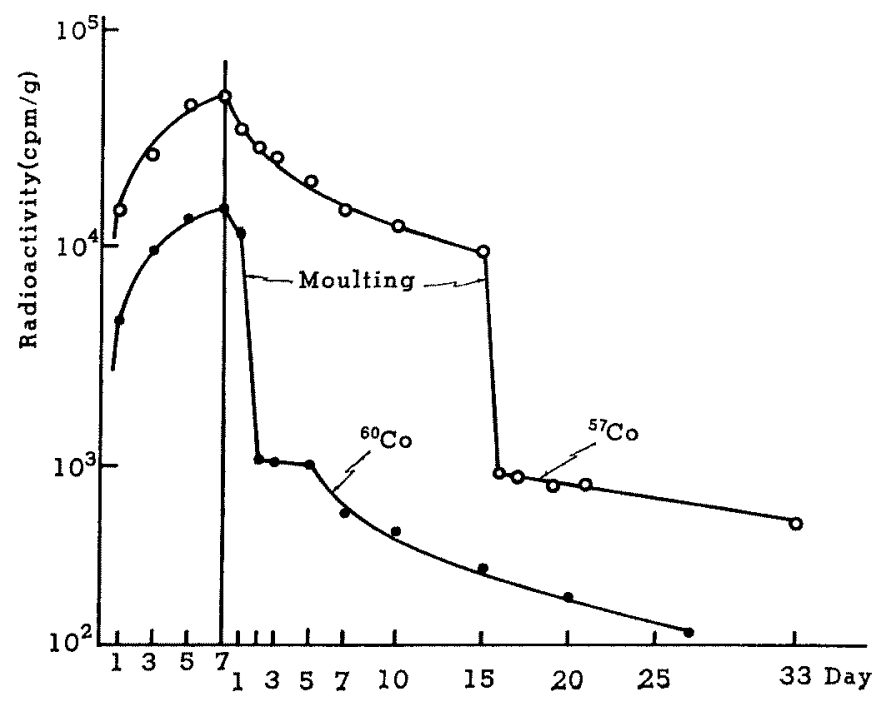

Fig. 3. Relationship between excretion of radioactive cobalt and moulting of prawn Penaeus japonicus. 
Table 1. Distribution $(\%)$ of radiocobalt in prawn on the 7 th day after exposure

\begin{tabular}{|c|c|c|c|c|c|}
\hline & \multirow{2}{*}{ Weight $(\%)$} & \multicolumn{2}{|c|}{ Inorg. Co in sea water } & \multicolumn{2}{|c|}{ Org. Co in sea water } \\
\hline & & Distribution $(\%)$ & $\mathrm{AR}^{*}$ & Distribution ( $\%)$ & AR* \\
\hline Shell & 20.0 & 40.7 & 13 & 31.2 & 49 \\
\hline Muscle & 44.5 & 1.2 & 0.2 & 0.8 & 0.6 \\
\hline Liver & 2.7 & 2.1 & 25 & 0.3 & 3 \\
\hline Gill & 1.2 & 7.5 & 40 & 34.6 & 640 \\
\hline Legs & 9.1 & 38.1 & 26 & 21.1 & 50 \\
\hline Eyes & 1.3 & 0.3 & 1 & 0.7 & 16 \\
\hline Intestine & 0.3 & 0.7 & 13 & 0.1 & 9 \\
\hline Stomach & 1.2 & 0.4 & 2 & 0.1 & 3 \\
\hline Others & 19.7 & 9.0 & 3 & 11.1 & 39 \\
\hline Whole body & 100.0 & 100.0 & 7 & 100.0 & 27 \\
\hline
\end{tabular}

* AR: concentration of radiocobalt in organism

concentration of radiocobalt in sea water

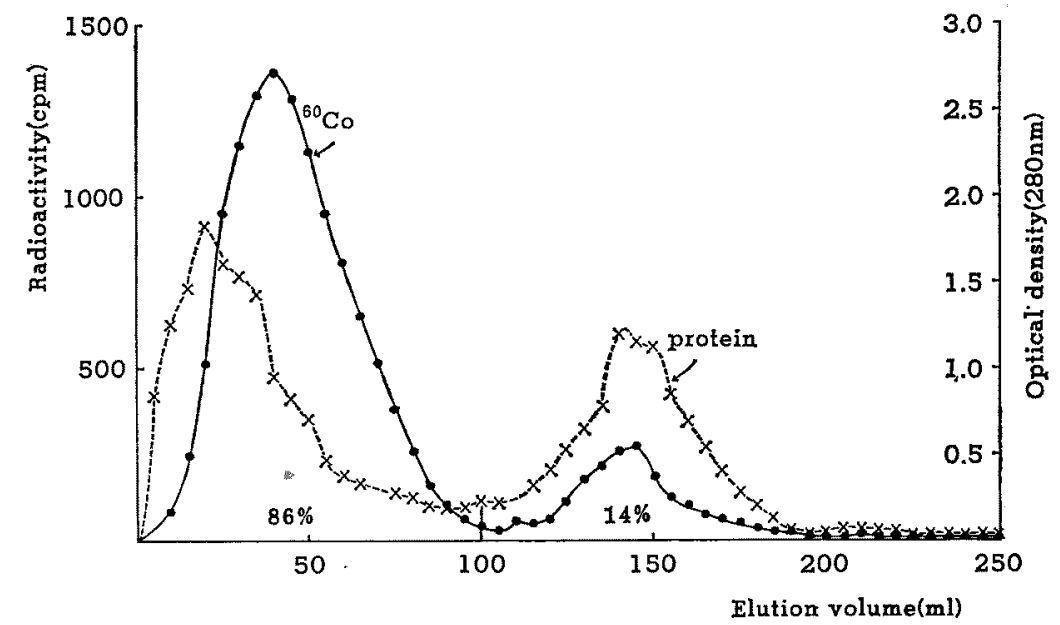

Fig. 4. Cobalt-60 gel filtration profile on Sephadex G-75 in the body (without intestine) of sea cucumber Stichopus japonicus.

So, eacn near $90 \%$ of the radioactivity of both ${ }^{87} \mathrm{Co}$ and ${ }^{80} \mathrm{Co}$ were lost by moulting characteristic of crustacea (Fig. 3). Moulting is one method for excretion of not only the end products of purine catabilism, ${ }^{13)}$ but also the radiocobalt adsorbed to the exoskeleton surface. Table 1 shows a distribution $(\%)$ of radiocobalt in prawn on the 7 th day after expostre. The sum of the distribution in shell, gill, legs, eyes and a part of others reaches over $90 \%$ in both cases of ${ }^{57} \mathrm{Co}$ and ${ }^{80} \mathrm{Co}$, however its specification is much different, especially in the gill. Although the distribution percent in the gill, when uptake of inorganic cobalt in sea water occurred, was only $7.5 \%$, that, when uptake of organic cobalt in sea water occurred, was over $34 \%$. Therefore, the radioactivity ratio (AR) of the gill under the presence of organic cobalt in sea water was approximately 16 times higher than that under the presence of inorganic cobalt. The organic cobalt may be physicochemically adsorbed on the gill surface rather than metabolically concentrated through blood.

\section{Binding of Radiocobalt to the Constituents in the Samples}

Fig. 4 shows elution profiles of optical density at $280 \mathrm{~nm}$ and of ${ }^{80} \mathrm{Co}$ radioactivity in the body (without intestine) of sea cucumber. Most radioactivity $(86 \%)$ was found in a higher molecular weight fraction and the ${ }^{80} \mathrm{Co}$ peak appeared on the leading edge of optical density peak, and the rest appeared in another fraction, which was eluted at the bed volume of the column, indicating that it contained relatively low molecular weight com- 


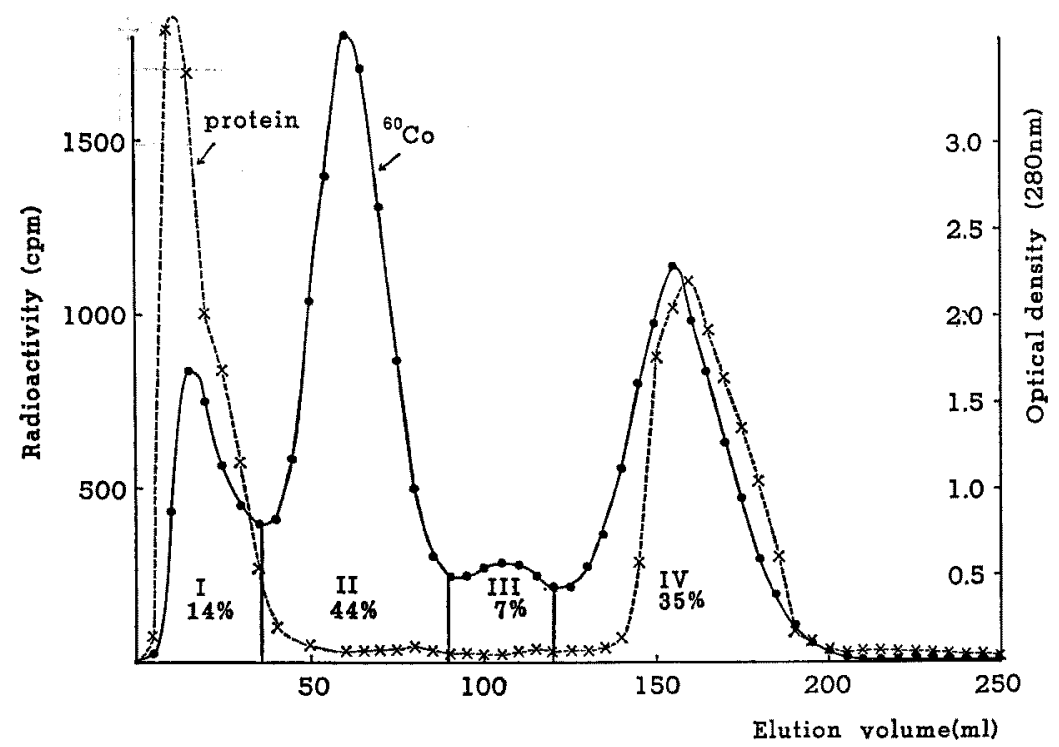

Fig. 5. Cobalt-60 gel filtration profiles on Sephadex G-75 in the intestine of sea cucumber Stichopus japonicus.

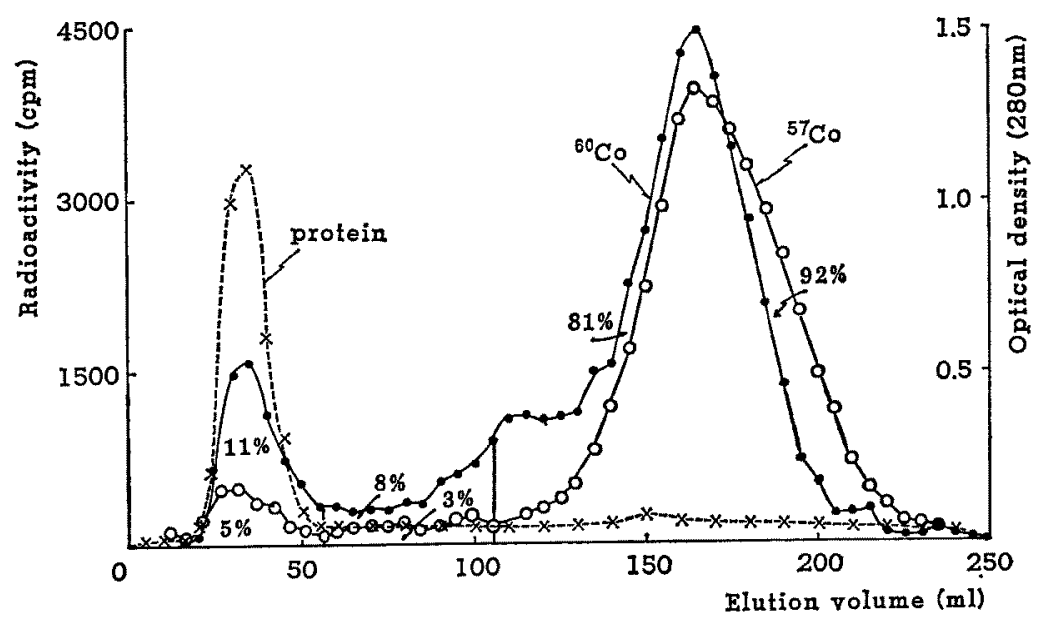

Fig. 6. Geliffiltration profiles on Sephadex G-75 of organic cobalt-57 and inorganic cobalt-60 in the liver of prawn Penaeus japonicus.

ponents. This elution pattern was similar to those in the case of fish ${ }^{12)}$ and molluscus. ${ }^{18)}$ However, as shown in Fig. 5, the ${ }^{80} \mathrm{Co}$ profile in the intestine of sea cucumber has four radioactivity peaks, i. e., those with a constituent with a molecular weight in excess of 80000 (Fraction I), 20000-30000 (Fraction II), around 10000 (Fraction III) and less than 5000 (Fraction IV). Although Fraction I (14\% of the total radioactivity) and IV (35\%) coincided in position with the optical density peaks, no optical density peaks corresponding to Fraction II
$(44 \%)$ and III $(7 \%)$ were present. This suggests that there are small quantities of protein which have particularly a strong afînity for cobalt, and otherwise any other components-probably carbohydrates.

Fig. 6 shows gel filtration profiles on Sephadex G-75 in the liver of prawn labelled separately for a week through sea water containing organic cobalt-57 or inorganic cobalt-60. Most radioactivity was found in a low molecular weight fraction despite little optical density peaks in both cases of 


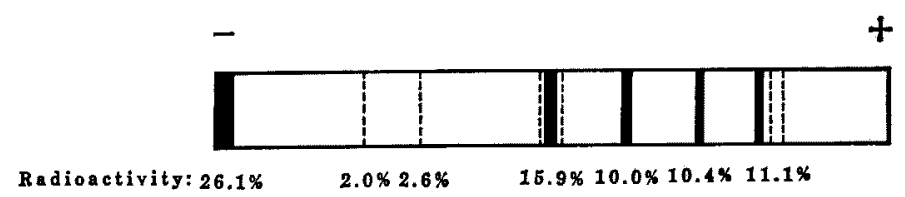

Fig. 7. Electrophoretic pattern on $6.5 \%$ polyacrylamide gels of the low molecular weight fraction from the G-75 chromatography in the prawn liver.

${ }^{57} \mathrm{Co}$ and ${ }^{60} \mathrm{Co}$. About $11 \%$ of the total radioactivity in the crude extract of the liver was bound to the high molecular weight constituents $(>80000)$ and this peak of ${ }^{60} \mathrm{Co}$ containing fraction coincided with the optical density peak. The binding of cobalt to the constituents with the molecular weight of about $\mathbf{1 0 0 0 0}$ was observed only in the case of inorganic cobalt. This suggests that the metabolism of cobalt in prawn may possibly be varied by the chemical forms of cobalt in sea water.

Carbohydrates are stored in the liver as glycogen, a polysaccharide built of glucose units. From analysis for carbohydrates, the total carbohydrate content in the liver was determined as approximately $1 \%$ on a wet weight basis. A large portion of cartohydrate was found in the high molecular weight fraction on the basis of analysis of the eluant fractions from the G-75 column, however the two low peaks which indicated the presence of carbohydrate were observed in positions coinciding with the radioactivity peaks. Further characterization of the ${ }^{80} \mathrm{Co}$-binding components around the peak of the low molecular weight fraction was achieved by electrophoresis on polyacrylamide gels, as illustrated in Fig. 7. This fraction contains at least $4{ }^{\circ 0} \mathrm{Co}$-binding proteins or peptides. However, components corresponding to about $26 \%$ of the total radioactivity did not show electrophoretic mobilities, indicating the ${ }^{80} \mathrm{Co}$-binding to carbohydrates.

Thus, radioactive materials, taken up by sea cucumber and prawn through sea water, are organically bound to a considerable number of proteins and carbohydrates in their organs and tissues, however the chemical identity and, in particular, the molecular structure and biological function of radionuclide binding proteins are little known. The biological role and detailed chemical nature of the components await further study.

\section{Acknowledgement}

The authors wish to express their cordial thanks to Mr. S. ToKoshima and his stuffs, Thermal Water Aquaculture Developement Association of Japan, for the offer of sample organisms.

\section{References}

1) Y. Suzuki, M. Nakahara, and R. Nakamura: Bull. Japan. Soc. Sci. Fish., 44, 325-329 (1978).

2) Y. Suzuki, M. Nakahara, and T. Ueda: Bull. Japan. Soc. Sci. Fish., 45, 1293-1298 (1979).

3) M. Nakahara, S. Hirano, T. Ishur, and T. KoYANAGI: Bull. Japan. Soc. Sci. Fish., 45, 14231428 (1979).

4) T. UEDA, Y. SuzukI, M. NakahaRA, and R. NAKamura: J. Radiat. Res., 23, 99-104 (1982).

5) Y. Suzuki, M. Nakahara, R. Nakamura, and T. UEdA: Bull. Japan. Soc. Sci. Fish., 45, 14091416 (1979).

6) M. Nakahara and F. A. Cross: Bull. Japan. Soc. Sci. Fish., 44, 419-425 (1978).

7) Y. Suzuki, R. NAKAMura, and T. Ueda: $J$. Radiat. Res., 17, 115-126 (1976).

8) T. Ueda, R. Nakamura, and Y. SuzUKI: Bull. Japan. Soc. Sci. Fish., 42, 299-306 (1976).

9) T. Ueda, R. Nakamura, and Y. Suzuki: $J$. Radiat. Res., 18, 84-92 (1977).

10) T. Ueda, R. Nakamura, and Y. SuzukI: $J$. Radiat. Res., 19, 93-99 (1978).

11) T. Koyanagi: in "Radiation Effects on Aquatic Organism" (ed. by N. Egami) Japan. Sci. Soc. Press, Tokyo, Univ. Park Press, Baltimore, 1980, pp. 27-37.

12) Y. Suzuki, R. Nakamura, M. Nakahara, and T. Ueda: Bull. Japan. Soc. Sci. Fish., 47, 261265 (1981).

13) T. Ueda, Y. SuzuKt, R. Nakamura, and $M$. NAKAHARA: IAEA-SM-248/130 (1980).

14) R. Nakamura, M. Nakahara, T. Ism, T. Ueda, and C. Shimizu: Bull. Japan. Suc. Sci. Fish., 46, 757-762 (1979).

15) M. Dubois, K. A. Glles, J. K. Hamilton, P. A. Rebers, and F. Smith: Anal. Chem., 28, 350 (1956).

16) Z. Ogita, and S. Nakamura: in "Denkieidojikkenho" (ed. by Nippon Denkieido-gakkai), Bunkodo, Tokyo, 1976, pp. 167-213.

17) E. Gilat: in "Management of Environment" (ed. by B. Patel) Wiley Eastern limited, New Delhi, Bombay, Calcutta, 1980, pp. 399-408.

18) W. B. Vernberg, and F. J. VernBerg: in "Environmental Physiology of Marine Animals" Springer-Verlag, New York, Heidelberg, Berlin, 1972, pp. 126-133. 